\title{
Plasticity and Creativity in the Logic Notebook
}

\section{Fernando Zalamea}

\section{(2) OpenEdition}

\section{Journals}

Electronic version

URL: http://journals.openedition.org/ejpap/593

DOI: 10.4000/ejpap.593

ISSN: 2036-4091

\section{Publisher}

Associazione Pragma

\section{Electronic reference}

Fernando Zalamea, «Plasticity and Creativity in the Logic Notebook », European Journal of Pragmatism and American Philosophy [Online], V-1 | 2013, Online since 16 July 2013, connection on 01 May 2019. URL : http://journals.openedition.org/ejpap/593 ; DOI : 10.4000/ejpap.593

This text was automatically generated on 1 May 2019.

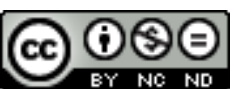

Author retains copyright and grants the European Journal of Pragmatism and American Philosophy right of first publication with the work simultaneously licensed under a Creative Commons AttributionNonCommercial-NoDerivatives 4.0 International License. 


\title{
Plasticity and Creativity in the Logic Notebook
}

\author{
Fernando Zalamea
}

\section{The Manuscript: Creative Reason and Plastic Imagination}

1 The Logic Notebook (LN) is a notebook ${ }^{1}$ where Peirce annotated chronologically (1865-1909) the emergence of some of his major ideas in logic and semiotics. The manuscript, lying in Harvard's Houghton Library, is registered in Robin's catalogue as (MS 339). The notebook is constituted by approximately 375 folios (recto/verso) which correspond to 530 written pages (many versos untouched). The $L N$ was perused extensively by Don Roberts in the 1960's, while preparing his Ph. D. Thesis on the existential graphs. Roberts proposed the name "Logic Notebook," produced a reasonable pagination and provided the actual or dering of the manuscript. Since then, only 35 pages have been published: Fisch 1966, 3 pages on triadic logic; Eisele 1985, 3 pages on classes; W 1.337-350, W 2.1-10, W 4.214-217, 29 pages on general logical arguments and on the calculus of relatives. Apparently, no fragment of the $L N$ was published in the Collected Papers, nor in New Elements of Mathematics.

2 Peirce's annotations register some of his first thoughts on logical subjects, with very diverse fragmentation levels, from isolated scraps to extended first versions of articles, projects or conferences, going through multiverse conceptualizations, definitions, systematizations and calculations. The chronological development of the material can be studied with rigor, thanks to the marks (day, month, year) that Peirce himself wrote on top of the pages (handwritten or, at the end, with a mechanical dater). A fourth part of the manuscript covers the period 1865-1897, and the other three fourths the period 1898-1909. The $L N$ is, thus, articularly useful for understanding the late Peirce, and, in particular, the emergence of the existential graphs and the semiotic classifications. 
The fundamental interest of the $L N$ consists in providing us a privileged laboratory of creativity. The creative mind, and in particular the creative scientist, has a tendency to erase the intermediate paths in her discoveries/inventions, once the work approaches some consistent final results, the ones that are circulated to the community of inquirers. The $L N$ allows, instead, to track many intermediate modulations between Peirce's initial, abductive guesses and its posterior, better achieved expressions. A register of practices of the scientist emerges, with explicit marks in the process of discovery. Through advances day by day, in some cases, and with sudden bursts of imagination, in other cases, the $L N$ yields a genuine vision of the creative web. In fact, the $L N$ - true index of invention - can be understood as an exceptional plastic register of obstructions (2), openings (1) and transits (3), where the esthetic freshness of the annotations confirms the so-called logic of research: combination of problems ("walls" in the original Greek) (2), regulating hypotheses (1), trial and error tests (2) and partial proofs (3).

4 The great critic and historian of art, Pierre Francastel, has underscored forcefully how mathematics and art should be understood as the two major polarities of human thought. Beyond mathematics and art, Francastel observed, in turn, the emergence of creative webs with multisorted mixtures: real and ideal, concrete and abstract, rational and sensible. A mediating system if there is one, Peirce's architectonics helps to calibrate those gluings between reason and imagination, and to situate "topographically" many of their diverse instantiations. It is well known how, in the late Peirce, esthetics becomes one of the foundations of logic (Parret 1994). Imagination transforms itself into a pillar of reason, confirming Pascal's dictum: "the heart has its reasons, of which reason knows nothing." The basis of Peirce's inversion consists in recognizing the esthetic summum bonum as a profound form of reasonableness, a sort of continuous growing of potentiality. ${ }^{2}$ Normative sciences emerge then as progressive approximations to the summum bonum: esthetical works as first embodiments (sensibility/creativity), ethical norms as second embodiments (action/community), logical systems as third embodiments (necessity/thought). Then, everything turns out to be modulation of an archetypical force, the summum bonum, which subdetermines its further evolution.

We propose to define the continuity/plasticity dialectics through the following Pascalian "reasons":

continuity

general intrinsic structuration plasticity

general extrinsic transformation

6 In this way, Peirce's summum bonum, as stated in 1905, where existence embodies progressively the general, lies on the plasticity (and esthetic) side, while continuity and mathematics serve as counterweights - in their primary studies of intrinsic structures to situate further esthetic embodiments. In fact, we are facing a double spiral, reflexive and iterative, here, on one side, mathematics as pure, first, imagination supports globally a mixed, second, esthetic creativity, which in turn supports logical, third reasons, but, on the other side, diverse mathematical fragments, viewed as consistent reasons, are locally supported on esthetic forms which, later, help to liberate the logical imagination (Shelah, the greatest living logician, proposes for example a typology of "reasons" to work in Set Theory, where "beauty" stands on top, well above any other methodological, logical or technical consideration [Shelah 2002]). 
We are thus in presence of a fundamental adjunction, easily expressed in a simple slogan: potentiate its growing (summum bonum), reason requires plasticity, while imagination requires exactness.

8 A fact not sufficiently emphasized, we believe that Peirce may well be considered as one of the greatest imaginative powers in the history of thought. Jakobson already signaled Peirce's profound originality, but it is difficult not to perceive that most of his interpreters (and some of his best readers, as Murphey, Hookway, Parker or Short) lack almost completely of the needed imagination to evaluate and appreciate Peirce's inventiveness. In that order of ideas, the absence of any monograph in English on Peirce's creativity is extremely telling (something which also points to the importance of Barrena 2007). It is just an aberrant situation since, in fact, most of the decisive Peircean advances constitute extraordinary forms of invention: globally, the cenopythagorean categories, the (fully modal) pragmaticist maxim, the dyad synechism/tychism, the universal semiosis, or, locally, the gravimetric measures, the relative calculus, the existential graphs, the dynamical interpretants. Such a wide and profound range of original production cannot be understood without situating, on front of the arguments, esthetical and plastic considerations. In fact, an understanding of Peirce's creative impulses requires to understand a multiverse web of contaminations, mixtures, blends, translations. In the next section we will immerse ourselves in precise examples of creativity in the $L N$, where many modes of plastic transformation become crucial.

\section{Case studies in the Logic Notebook}

9 The emergence of new ideas abounds along the $L N$, since Peirce seems to have con- structed the habit of turning to the notebook in many of those "moments privilégiés" (Proust) related to the opening of creative possibilia. In this section we will investigate five case studies which express well that creative emergence: (A) differential relatives (November 1868), (B) existential graphs (June 1898), (C) sequence diagrams (August 1898), (D) triadic logic (February 1909), (E) translatability (October 1898). In many of those moments, mathematics, logic, semiotics and philosophy are mixed to produce new ideas, and a general transgression process is at the bottom of their originality.

\section{A. Differential Relatives (November 1868)}

Between November 8 and 15 1868, the $L N$ registers diverse essays to construct a calculus of differential relatives ( $L N, 46 r-67 r$ ). An extensive number of pages betrays Peirce's agitation in that week. Preceding the major article on the subject (Peirce 1870), the long sketch in the $L N$ enters the realm of a speculative differential version of the relative calculus, which is not mentioned afterwards in the 1870 article. Motivated by Boole's analytical treatment of logic, Peirce tries to transgress the traditional conception of logic (study of finite laws of thought) and proposes, instead, to use a more sophisticated mathematical arsenal (infinite webs of analysis) to reveal other invariances and, as we shall see, other logical obstructions.

11 Peirce's annotations begin with the sentence "In short there must be a Middle Voice" (46r, Peirce's capitals). Peirce thus sketches, since November 1868, a logic of differential mediations ("Middle Voice"), that is, an early logic of continuity, a middle-way logic of 
"being." The multiplicity of exponentials will emerge again, years ahead, through the multiplicity of possibilia in Peirce's continuum. Peirce's writings present a fascinating series of daily progresses and retreats, calculus exercises and conceptual discussions, failed trials, erasures, crossing-outs, and permanent verbal modalities ("may," "can," "must," etc.) The inquirer fights with himself: "Here I feel myself sadly in want of a better notation," "This development does not hold," "I want some thing similar" (46v), "How the inverse should be," "My analogies so far are but remote. Still I hope they will develop into something" (47r). Since the very first pages, Peirce begins to combine notations (algebraic and diagrammatic) and to suggest analogies (relative and analytical exponentials), immersed in a mud where lights are absent but where confidence ("Still I hope") may orient new findings.

Days go by, and Peirce works with a multitude of techniques -quantifier approximations (44r), comparisons with De Morgan (a5r), algebraic developments (52v), lattice arguments (55r), Taylor's theorem (57v), differential remainders (59v), general binomial developments (60v)- until getting again insuperable obstructions ("There must be some mistake here," "I drop this here for the present" (62r)). Nevertheless, only a day later, he takes up again what was apparently left over: he discovers the reason of all complications in the non-commutative treatment of the relative differential exponential that he has been trying to introduce, and begins to elaborate a list of its peculiar properties ("I will now note all the exceptions in reference to these exponents" (62v)). The introduction of generalized logarithms (63r-66r) helps to explain the exceptions, but the annotations finish abruptly, concluding a week of extraordinary fizziness.

13 A long year elapses before Peirce, on October 15 1869, writes finally his "Eureka" (see figure 1). The exclamation is related to the conscience of an unusual state of things: the non-commutativity and the absence of unit for certain logical first-order operations, a profound discovery, well ahead in time, which would take a century in being understood (through the exponentials in Girard's linear logic). One can observe how Peirce's creativity fully profits from the means available: contamination of logic and mathematics, transgression and new adaptation of signs, possibility of alternative laws. It reflects the plasticity of a non-dogmatic researcher, open both to variable conjectures (through daily corrections and doubts) and to steady alternative laws in the longue durée. Mark of a genius, reverse paths and doubtful mistakes pave the way to unsuspected possibilities of growth. 


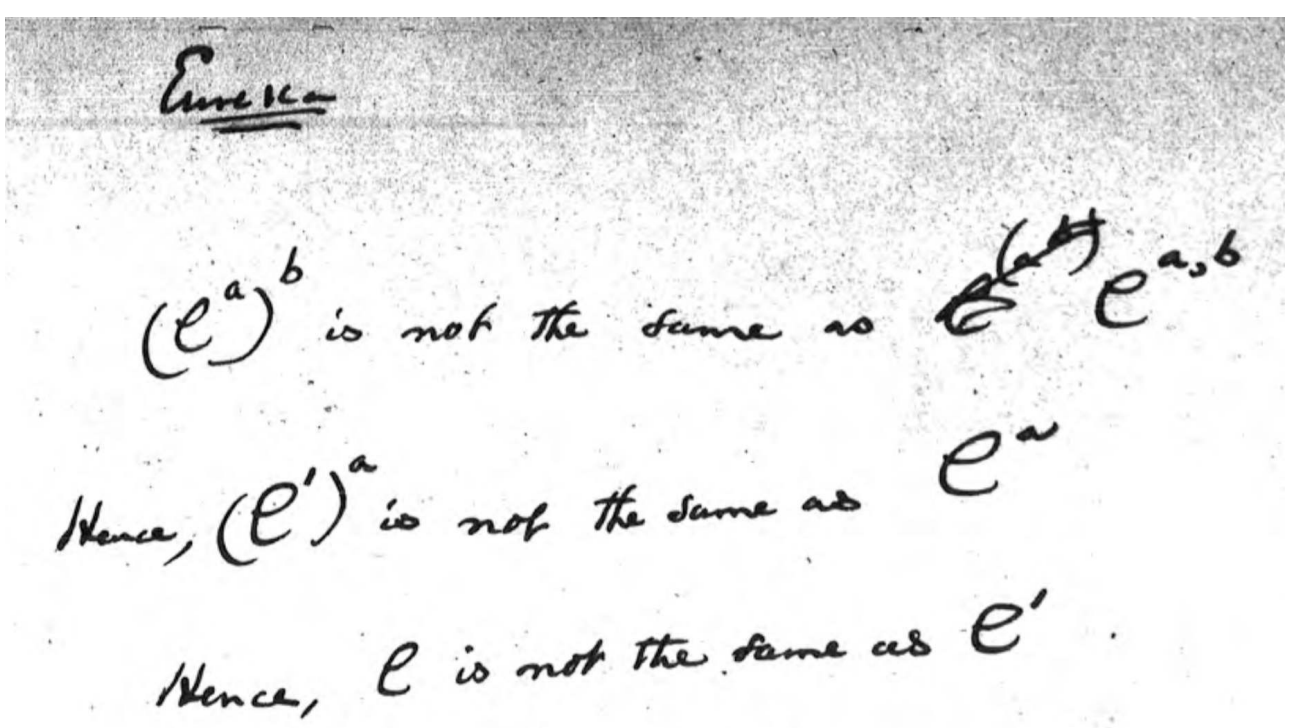

Peirce's essays on the differential relatives constitute a good example of mixed and transformative creativity. A back-and-forth between obstructions and transits flows all over Peirce's thought, first, bounding every failure, every doubt, every sign of despair, and reflecting, after, on each of those limitations, at many levels, notational, definitional, calculative or conceptual. Stunningly, the pragmatic maxim governs thus Peirce's very inventive trance. The transformations of signs -floating or sinking on a sea of apparently disparate analogies- generate, in a very concrete and material way, new ideas.

\section{B. Existential Graphs (June 1898)}

If the differential relatives constitute an "obscure" chapter in Peirce's creativity, somewhat sunken in the $L N$, the emergence of the existential graphs in the $L N$ can be seen, instead, as one of its most luminous moments. Recognized by Peirce himself as his "chef d'oeuvre," the graphs may well be considered, a century later, not only as Peirce's master work, an exceptional reflection of his architectonics, but also as one of the most remarkable inventions of the entire history of logic. The graphs include in fact, with the utmost economy, (i) (syntactics) a unique diagrammatic language, (ii) (pragmatics) archetypical rules for the uniform handling of multiverse logics, propositional, first-order or modal, and (iii) (semantics) a wide variety of models of profound mathematical richness, topological (Burch), intuitionistic [Oostra 2010, 2011], categorical (Brady and Trimble) and analytical (in the sense of complex variables, Zalamea) (for an overview of all these contributions see Zalamea 2010).

At the end of his life, Peirce sketched a brief genealogy of the graphs, affirming that he had discovered them in January $1897 .{ }^{3}$ We have no record that Peirce's affirmation has been confirmed by any inspection of his manuscripts, but, instead, it is certain that the first appearance of the graphs in the $L N$ occurs only one year and a half later, on June 9 1898 (102r). It is the beginning of a first draw of a systematic ${ }^{4}$ rendering of the graphs "Existential Graphs: a system of logical expression. The Constitutive Conventions of this Language" (102r, Peirce's capitals) - where the emphasis lies on expression and language. Hours later, still on June 9, Peirce writes a third draw, with a small but significant 
variation in the title: "Existential Graphs. The Constitutive Conventions of this system of assertion expression" (105r, Peirce's crossing-out). "Language" passes thus to a second plane. Five days later, the seventh draw is titled "Basic Formal Rules, from which, without reference to the Constitutive Conventions, all illative transformations can be deduced" (112r). The previous constitutive references to language are thus forced to disappear. Between June 14 and June 19, all of Peirce's efforts (112r-125r) are concentrated in specifying, with great care, the "Basic Formal Rules" of the logical system and in emphasizing repeatedly its pragmatic aspect.

17 A comparison of the diverse versions shows us how Peirce becomes growingly conscious of the pragmatic specificity of his system, introducing many short and beautiful proofs that illustrate the strength of the rules. All is beauty, for example, in Theorem XIX (117r) where Peirce proves the consistency of his system (in a same region, one cannot draw simultaneously $a$ and $a$ ). A counterpoint harmony between erasure and insertion imposes on the Reader. In a similar vein, Theorem XXVI (120r) proposes normal forms for the quantifiers, where the breaks and gluings of the line of identity codify a very beautiful diagrammatic dance on the page (see figure 2). The transformation of images not only reveals underlying logical codes, but also a profound esthetic equilibrium.

FIgURE 2. QUANTIFIER TRANSFORMATIONS (LN, 120R)

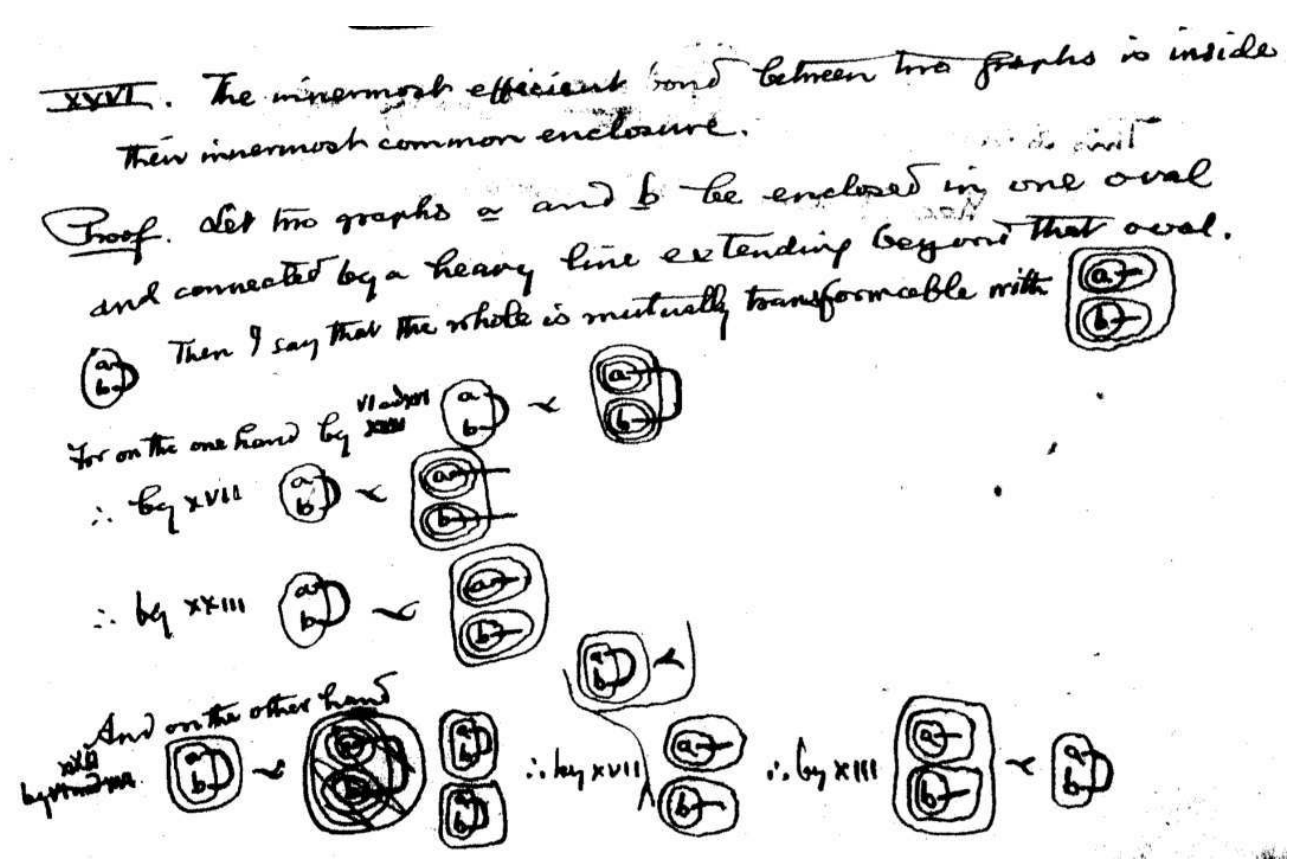

In Peirce's creative skills we thus observe how the scientist accepts the mud, decants it analytically, manipulates it pragmatically and, finally, finds novel synthesis. ${ }^{5}$ In fact, we are looking to an inquirer which situates itself naturally in a middle-way between analysis and synthesis (for developments see Maddalena and Zalamea 2011). The transgression of any absolute perspective (either analytical or synthetic) is fundamental to allow the plasticity required by the creative mind. 


\section{Sequence Diagrams (August 1898)}

Little after the first entries on existential graphs in the $L N$ (102r-127r), Peirce embarks on another unexpected adventure, in which he tries to understand visually some metaproperties of sequences, with the objective of presenting diagrammatically the properties of natural numbers (already axiomatized algebraically in Peirce 1881, see Oostra 2003 for a detailed study). On August 4 1898, Peirce writes: "We now come to An Extension of Existential Graphs, permitting Abstraction," where "Abstraction consists essentially in regarding a set of things, ordered or unordered, as an individual object, and denoting it by an index" ( $L N, 128 \mathrm{r})$. Dealing with abstractions in Beta is a daunting enterprise, that Peirce would never complete, ${ }^{6}$ even if the discernment of the seer astonishes us: "But it is hard to define a 'set' of things. Since, then, the idea of a sign is presupposed in logic, it is better to endeavor to define abstraction in terms of signs instead of sets" (128r, Peirce's emphasis), "Try to define a pair, an ordered pair. You are driven to the idea of a sign" (129r). The control of an abstraction must be, thus, the control of its signs: a simple form of asserting that the control of a concept consists in the control of its representations in formal systems, the basis of XXth century mathematics.

Peirce creates diverse signs to capture the idea of a sequence. He introduces first a new sign (sort of eagle wings, 129r) to express the ordered pair, then introduces another original sign (sort of inverted heart, 130r) to express belonging, and he begins to combine them under Beta to express order properties (August 4, first fragment of figure 3), sequences properties (August 5, second fragment of figure 3) and natural number properties (August 6, third fragment of figure 3). Again, we stand in front of intense days of sowing, that, without enough fertilizers, dry soon. But, even if the days of harvest were not meant to be Peirce's, it is still amazing to sense his great vision.

FIgURE 3. DIAgRAMMINg PROPERTIES OF SEQUENCES (LN, 131R, 136R, 139R)

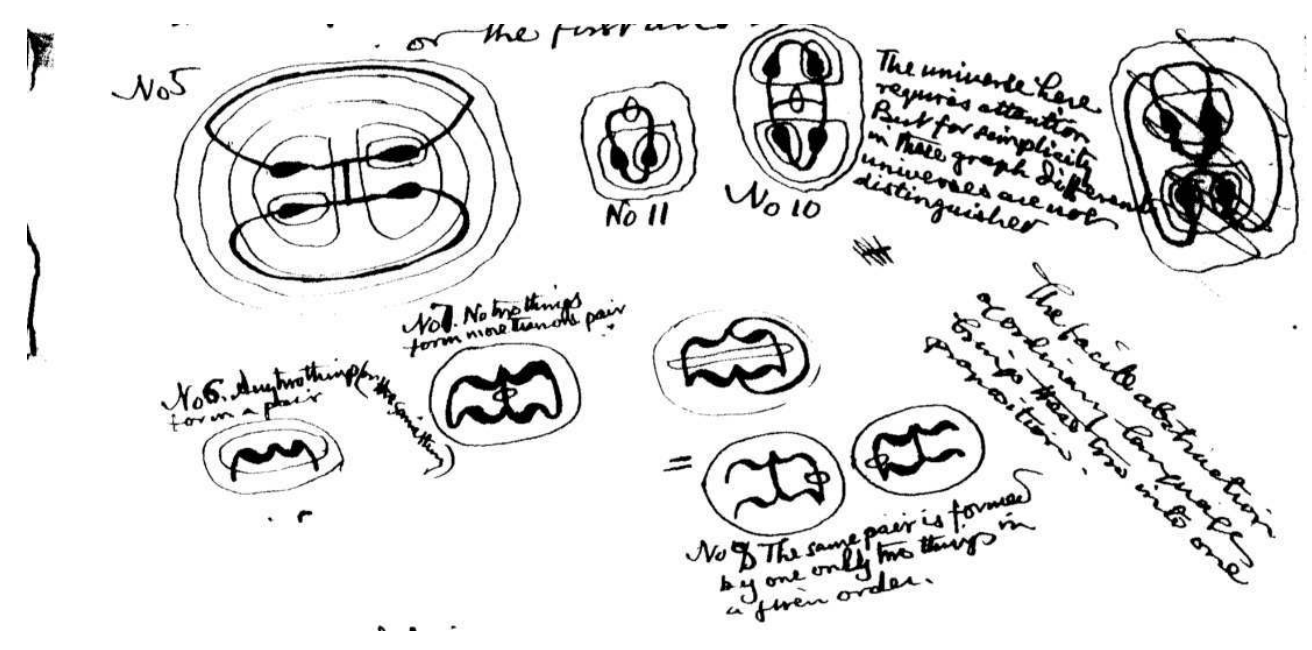



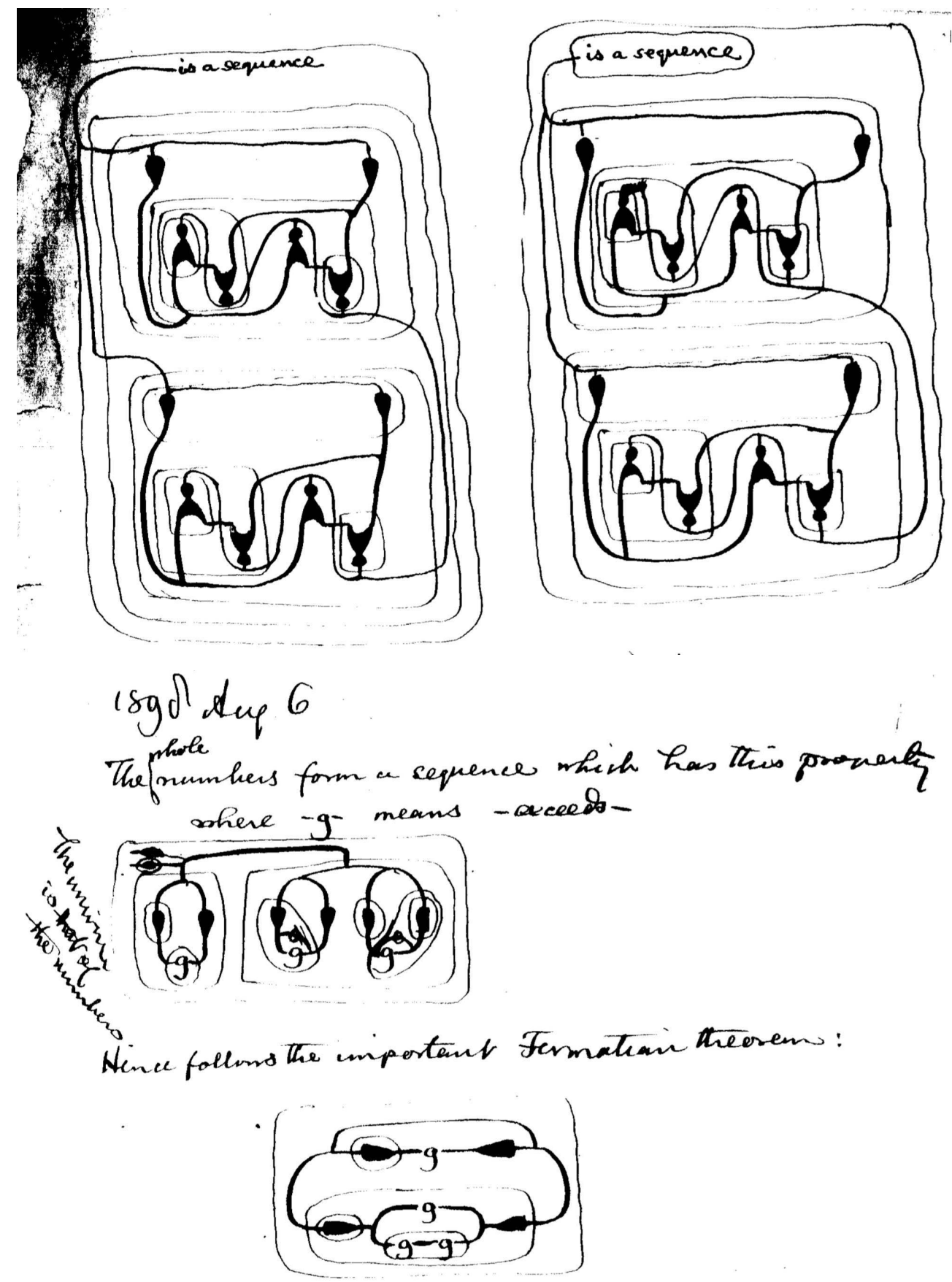

Peirce's visual imagination multiplies over approximately fifty (!) diagrams produced in three days (128r-150r). The construction guides for the diagrams are clearly esthetical: progressive elegance of the sign to represent the ordered pair (129r, 130r, 134r), modification of distributions of identity lines to reach harmonic counterpoints (134r, 135r, 138r), coloration of black and red lines to produce tonal balances (136r), quest for visual nuclei susceptible of being iterated (136r, 137r, 139r). Very diverse contaminations between mathematics, esthetics and logic become enacted in those Peircean sketches. Inventiveness explodes thanks to the esthetic tensions between signs. Peirce's approaches to the summum bonum open a new door, completely abandoned in the history of thought since that August 1898: interlacing abstraction (logic) and order (mathematics) through visual harmonic equilibria (diagramming). 
In fact, even if abstraction, order and visual harmony have been embodied, for example, in the paintings of Rothko or in the sculptures of Caro, Peirce's heirs have still to understand that compelling mixture in mathematics. If Category Theory confirms itself as an appropriate general topos for such an encounter, if its technical expression turns out to be describable by the logic of Sheaf Theory, and if sheaf logic situates finally at the "heart" of a wider Synthetic Philosophy of Mathematics, then we could appreciate better the extraordinary power of the $L N$ seeds. Indeed, an invitation to imagine such an alternate program for Philosophy lay, technically, in Peirce's abstract visualization and, methodologically, in the contaminating transit efforts of the "cryptic" pages 128r-150r of the $L N$ : a true miraculous icon of Peirce's genius, that our Epoch still has to embody in its progressive concretion of the summum bonum.

\section{Triadic Logic (February 1909),}

Close to his final years, in another week of intense activity, between February 16 and February 23 1909, Peirce annotates in the $L N$ several attempts to construct forms of a triadic logic. The essays are situated between a triadic extension of the Pascalian triangle (December 27 1908, 333v), a modal problematic at bottom ("Studies of Modal, Temporal and other Logical Forms which relate to special Universes," February 16 1909, 341r) and a short observation on graph tinctures ("Note on the Tinctures," February 26 1909, 345r). Consequently, the emergence of triadic logic is not casual and answers partially some permanent queries of Peirce: cenopythagoreanism, modality, variation. Fisch 1966 has underscored the full importance of the ternary tables that appear in the $L N(340 \mathrm{v}, 341 \mathrm{r}$, $341 \mathrm{v}, 342 \mathrm{r}, 344 \mathrm{r})$, the first ones in the history of logic to try to formalize a modal triadic calculus (see also Oostra 2007).

On February 16 1909, Peirce begins with an analysis of the Boolean functions and establishes a minimal set of functional equations (341r), that, after, profiting from a blank verso in the preceding page, he extends to three values, proposing new truth tables for the connectives $(340 \mathrm{v}$, see figure 4). The proposals (rediscovered ten years later in Lukasiewicz's logic) are distributed along difficult calculations on the page, with a unique commentary by Peirce: "All this is mighty close to nonsense." Once more, penetrating on the borders of contradiction, coming from obscure layers, through crossing-outs and rewritings, through mixed non well-oriented essays, in short, coming from a muddy bottom, emerges the creative act. 


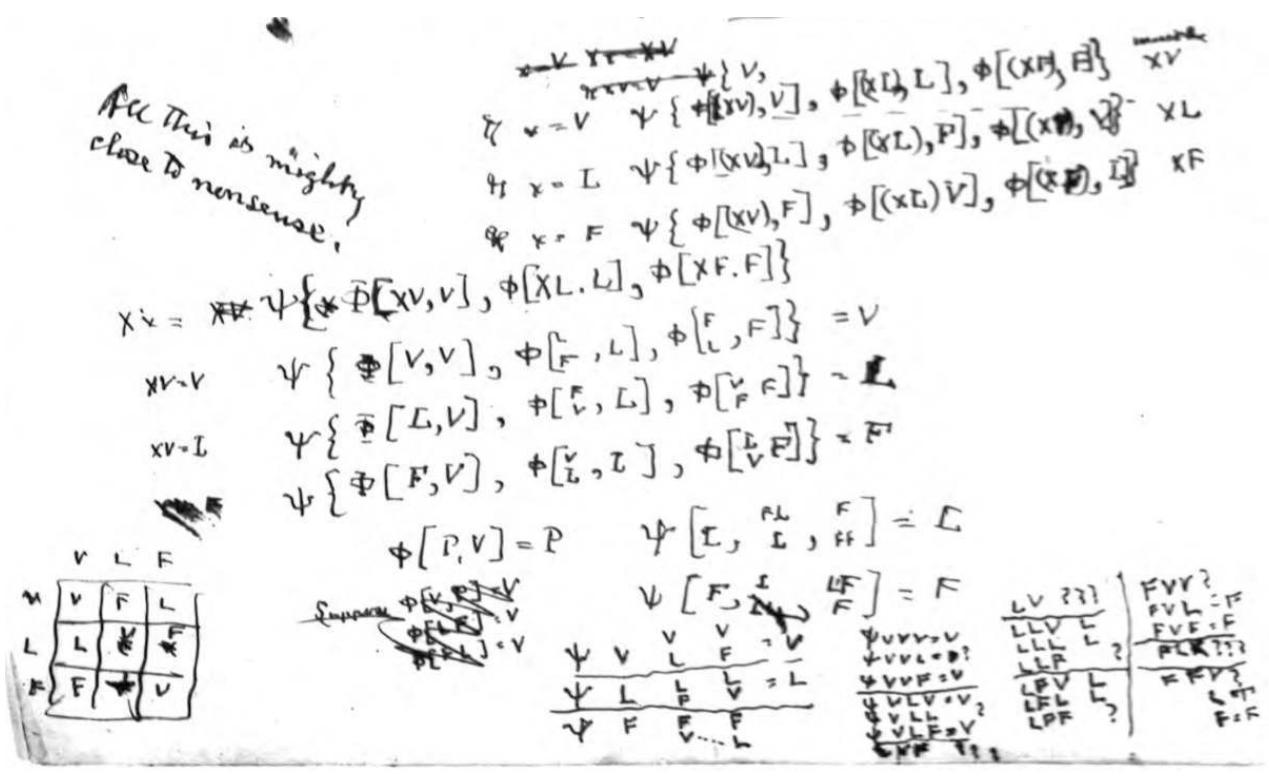

At the end of the February 16 session, Peirce writes: "Try the triadic system of values again." To the amazement of those which can now follow his annotations, we see how the functional equations of some triadic operators are then expressed in a perfectly clean way, and how Peirce proposes the tables of six (!) different triadic connectives (341v). The mental imagination work done between pages $340 \mathrm{v}$ and $341 \mathrm{v}$ is simply inconceivable. From the mud we pass to crystalline waters, through esthetic visualizations and structural equilibria which are not registered in the $L N$ and, thus, which may never have existed as external, concrete marks. We are in front of a fascinating process of mathematical invention, ${ }^{7}$ where the creative mind lucubrates on obscure images of tension and equilibrium, without marking or writing, until she attains, suddenly, the desired clearness.

In turn, the process may be viewed as a showing instance of Peirce's "scholastic realism": in the same manner as imagination of possibilia in mathematics does not require marks, the possibility of an understanding of real universals does not need to reduce itself to existence verifications. In fact, Peirce's last annotation on "Triadic Logic" (red title, February 23 1909, 344r) states: "Triadic Logic is universally true." That universal truth is another weaving form of Peirce's architectonics: if an advanced model for synechism was already present through the existential graphs, the new triadic logic could serve now as a nice model for the three cenopythagorean modalities. A stunning mind, Peirce continued to interlace the global and the local, the universal and the particular, the dynamical and the invariant: the true stamp of a genius.

\section{E. Translatability (October 1898)}

The force of creative processes, as Walter Benjamin's opus has shown, originates often in their translatable character. On one side, the creative mind translates texts, images, analogies between different fields of knowledge, and, on the other side, she transforms the closed boundaries of those fields in open frontiers. Many times in his life, Peirce went consciously beyond his mother tongue and made incursions in other languages (French, Greek, Latin, etc.; the list is long and includes Euskera...) Of major relevance can be 
considered the first version in French, in a ship between Hoboken and Plymouth, of his famous article How to Make our Ideas Clear (for a careful analysis, see Deledalle 1981). forms of invention. A plastic transformation -combination of free (universal) imagination and singular (particular) expression- is the very engine of creativity in those pages of the $L N$. After the first sentence of his "traité de logique," the singularity of the French expression liberates Peirce's imagination, and generates a turning point in Peirce, who writes 16 pages in four days, producing a surprising alloy of freeness, freshness and precision. From an imaginary mud and the contradictions of language emerges then the creative spark. Most of Peirce's annotations consist in an explanation, notably simple and well argued, of what will be his 1903 "perennial classification" of sciences [Kent 1987]. Even if Peirce had already proposed multiple classification patterns, those essays were long and artificial. It is remarkable that the very heart of the "perennial classification" occurs, instead, compactly presented in the $L N$ five years before.

31 Apparently, a visual perception of the classification (a typically Peircean activity that Kent resumes in her analysis) is combined in October 1898 with its French expression, an unexpected weaving which yields an evident simplification in its orderly presentation. Comte's typological clearness, or the French inheritance around "distinct reasons," may have exerted then a benefic action on Peirce's somewhat profuse and never-ending English.

Between October 1 and 4 1898, the $L N$ includes another revealing example of such a I am writing in this book, not this time parce que j'ai quelque chose de nouveux à laquelle je veux fixer la date, mais simplement parce que le papier que j'ai commandé pour écrire mon histoire de la science n'étant pas venu, je m'occupe cependant en faisant des notes pour un traité de logique. (151r)

writes on it in order to fix novelties. Peirce's student smiles at the lack of adequate paper, an intrusion of chance which transforms the action. The student of thought marvels at Peirce's desire to write a treatise of logic, just not to lose his time. But, above all, what sentence. Without forewarning marks, Peirce's mind imagines fragments of space ("book" "papier"), time neighborhoods ("this time" - "la date") and activities ("writing" "quelque chose de nouveux"), that only afterwards get transposed to a given language. In discontinuous expressions in reflexive languages (English, French). The germs of possibility -prototypes of space, time and relation- come before their later existence. Translation, situated at language level (ii), refers to a much more profound transformation at geometric level (i).

Translation and transformation, forcing him to think from the verso, crystallizes in this occasion in a pearl of elegant concision. 


\section{BIBLIOGRAPHY}

BARRENA S., (2007), La razón creativa. Crecimiento y finalidad del ser humano según C. S. Peirce, Madrid, Rialp.

DeledAlLe G., (1981), “English and French versions of C.S. Peirce’s «The Fixation of Belief» and «How to Make our Ideas Clear," Transactions Charles S. Peirce Society, 17, 141-52.

EISELE C., (ed.), (1985), Historical Perspectives on Peirce's Logic of Science: a History of Science, New York, Mouton.

FISCH M., \& A. TURQUeTte, (1966), “Peirce's Triadic Logic,” Transactions of the Charles S. Peirce Society, 11, 71-85.

KENT B., (1987), Logic and the Classification of Sciences, Montreal, McGill University Press.

maddalena G., \& F. Zalamea, (2011), “A New Analytic/Synthetic/Horotic Paradigm: From Mathematical Gesture to Synthetic/hHorotic Reasoning," Kurt Gödel Research Prize Fellowships, preprint.

oostra A., (2003), “Acerca del artículo On the Logic of Number de Charles S. Peirce,” Boletín de Matemáticas, Nueva Serie X (1), 14-21.

oostra A., (2007), "La lógica triádica de Charles S. Peirce," in Memorias XVIII Encuentro de Geometría y sus Aplicaciones, Bogotá, Universidad Pedagógica.

oostra A., (2010), “Los gráficos Alfa de Peirce aplicados a la lógica intuicionista," Cuadernos de Sistemática Peirceana 2, 25-60.

oostra A., (2011), “Gráficos existenciales Beta intuicionistas," Cuadernos de Sistemática Peirceana 3, 53-78.

PARRet H., (ed.), (1994), Peirce and Value Theory. On Peircean Ethics and Esthetics, Amsterdam, Benjamins.

PEIRCE C. S., (1870), "Description of a Notation for the Logic of Relatives, Resulting from an Amplification of the Conceptions of Boole's Calculus of Logic," Memoirs of the American Academy of Arts and Sciences, 9, 317-78.

PEIRCE C. S., (1881), “On the Logic of Number," American Journal of Mathematics, 4, 85-95.

Shelah S., (2002), “The Future of Set Theory,” [arxiv.org/pdf/math.LO/0211397.pdf].

Zalamea F., (2010), Los gráficos existenciales peirceanos. Sistemas de lógicas diagramáticas del continuo: horosis, tránsitos, reflejos, fondos, Bogotá, Facultad de Ciencias, Universidad Nacional de Colombia.

\section{NOTES}

1. Peirce mentions the $L N$ as "this book" ( $L N, 17 r)$. Our visit to Houghton Library (2008) confirms it, finding diverse booklets of what may have been the original Notebook, and keeping track of diverse perforations (now in separated sheets) which correspond to the original sewing of the 
book. The physical state of the manuscript is calamitous, but, fortunately, the $L N$ has been entirely digitized (2010), and is now available on line: [pds.lib.harvard.edu/pds/view/15255301].

2. "The pragmaticist does not make the summum bonum to consist in action, but makes it to consist in that process of evolution whereby the existent comes more and more to embody those generals which were just now said to be destined, which is what we strive to express in calling them reasonable" (CP 5.433; 1905, Peirce's emphasis).

3. "Owing to my Existential Graphs having been invented in January of 1897 and not published until October, 1906, it slipped my mind to remark when I finally did print a description of it, what any reader of the volume entitled Studies in Logic by Members of the Johns Hopkins University (Boston, 1883), might perceive, that in con structing it, I profited by entirely original ideas both of Mrs. and Mr. Fabian Franklin, as well as by a careful study of the remarkable work of O. H. Mitchell, whose early demise the world of exact logic has reason deeply to deplore" (CP $4.618,1908)$.

4. Which would confirm indirectly the previous existence of graph manipulations.

5. The construction of a Peirce supposedly anticipating Analytic Philosophy seems to have been just an ingenuous artificial interpretation at the end of $\mathrm{xx}^{\text {th }}$ century, which should have no course anymore.

6. From a logical (not mathematical) point of view, Peirce's enterprise was equivalent to control some sort of Set Theory over a reasonable quantificational calculus. The task took three decades (1895-1925), before the Zermelo-Fraenkel system fully emerged, based on first-order classical logic.

7. The process has been several times described since Poincaré. Grigory Perelman, recent inventor/discoverer of the proof of Poincaré's Conjecture, has described how the proof developed for months in his mind, without ever using a written account. Imagination in mathematics necessarily approaches imagination in art.

\section{ABSTRACTS}

Peirce's architectonics, far from rigid, is bended by many plastic transformations, deriving from the cenopythagorean categories, the pragmaticist (modal) maxim, the logic of abduction, the synechistic hypotheses and the triadic classification of sciences, among many other tools capable of molding knowledge. Plasticity, in turn, points to interlacements between mathematics and art, and shapes some associated conceptual forces in the boundary of the disciplines: variation, modulation and invariance; transformability, continuity and discreteness; creative emergence. In this article we focus on this third aspect, through bounded, well defined case studies in the Logic Notebook. The first section describes the manuscript and its interest for a study of creativity, leading to a short speculation on "creative reason" and "plastic imagination" in Peirce. The second section studies five precise cases of creative emergence in the Logic Notebook: differential relatives, existential graphs, sequence diagrams, triadic logic, translatability. Some major surprises occur in those detailed studies. 
AUTHOR

FERNANDO ZALAMEA

Universidad Nacional de Colombia

fzalameat@unal.edu.co 